\title{
Electricity demand management within the retail electricity market in Russia
}

\author{
Nikita Ogorodnikov ${ }^{1}$ \\ ${ }^{1}$ Melentiev Energy Systems Institute Siberian Branch of the Russian Academy of Sciences, Irkutsk
}

\begin{abstract}
Absract. Demand side management is an important tool for ensuring the flexibility of the electric power systems, as it maintains and regulates the balance of generation and consumption of electric energy and has a system-wide effect, which is formed by lowering electricity prices for consumers and optimizing the load and structure of generating and electric grid capacities. The article is devoted to the problem of managing the demand for electricity consumption within the framework of the retail electricity market in Russia. The author identifies and summarizes the existing demand management tools. The article substantiates the need for the development and implementation of innovative tools and mechanisms for managing the demand for electricity consumption.
\end{abstract}

Key words: Electricity demand management, electricity consumption, small motor consumers; load aggregators.

\section{Introduction}

Historically, the following priority tasks have been and remain in the development of the electric power industry:

a) Improving the quality and reliability of energy supply to consumers;

b)Reducing the number of accidents and failures in the operation of power equipment;

c) Reduction of electricity losses during generation and transportation;

d)Reducing the share of costs in the cost of electricity;

Over the last decade, the demand response has become a full-fledged tool for maintaining the balance of supply and demand in power systems. Managed demand is growing around the world; new types of consumers with different equipment are involved in demand management, new technologies and business models appear. Significant demand management potential is concentrated among consumers in the retail market medium and small, as well as in the household sector. Unlocking this potential requires the creation and implementation of new mechanisms for involving consumers in demand management. Demand response (DR) for electricity is the change in electricity consumption by end-users relative to their normal load profile in response to changes in electricity prices over time or in response to incentives aimed at reducing consumption during periods of high electricity prices in the wholesale market. The goal of power demand management is to level the daily electricity consumption by transferring power consumption from peak work hours of electric power systems to night hours or to periods of weekends and holidays (Fig.1) [1].

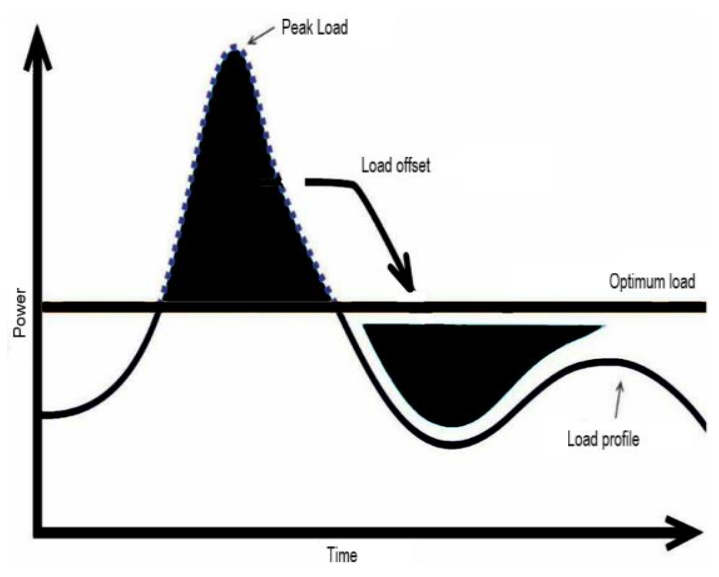

Figure 1. Demand management

Demand management lowers electricity prices in the wholesale market, which in turn leads to lower prices in the retail market, and in the long term avoids the construction of new power plants and networks to cover peak loads. According to various estimates, the potential for reducing the peak load in the power system due to demand management amounts $10-15 \%$ of the peak load $[2,3]$. Demand response (DR) serves as an important tool for solving these problems, since it maintains and regulates the balance of generation and consumption of electricity and has a system-wide effect formed by reducing electricity prices for consumers and optimizing 
the load and structure of generating and power grid capacities for the power system.

\section{The purpose and history of the appearance of the DR}

DR is a reasonable compromise for all participants in the production-transmission-consumption of electricity and provides them with certain benefits:

a) For consumers, it is expected to improve the energy-economic parameters of production based on increasing energy efficiency, rationalizing power consumption modes and reducing the cost of electricity.

b) For energy companies, the threat of loss of income due to the growth of inefficiently used generation is eliminated, and due to the decrease in the uncertainty of demand, the quality of planning for the development of energy capacities in the regions increases.

c) There is a development and maintenance of markets for the production, implementation and maintenance of energy efficient equipment, as well as energy saving services

d) The society as a whole benefits from the environmental effect in the production, transmission and consumption of electricity, obtained by reducing the amount of harmful emissions and losses of electricity.

At its core, a DR is an initiative form of economic interaction of energy supplying organizations with consumers, providing mutually beneficial regulation of volumes and modes of power consumption [2]. The essence of the DR lies in the purposeful and systematic impact of power companies on the volumes, structure and modes of power consumption in the region served. There exists the term 'Demand side management (DSM)', which is understood as an active form of economic interaction between energy supply organizations and consumers, providing mutually beneficial regulation of volumes and modes of electricity consumption. The term DSM originated during the 1973 and 1979 world oil crises [4]. In 1978, the United States passed the National Energy Conservation Policy Act and Charter and on their basis a set of energy demand management measures was developed. In some states, electricity demand management programs were legislated as early as 1975 [5]. DSM technologies are currently undergoing intensive development in such countries as the United States, Australia, India, China and Japan (Fig. 2).

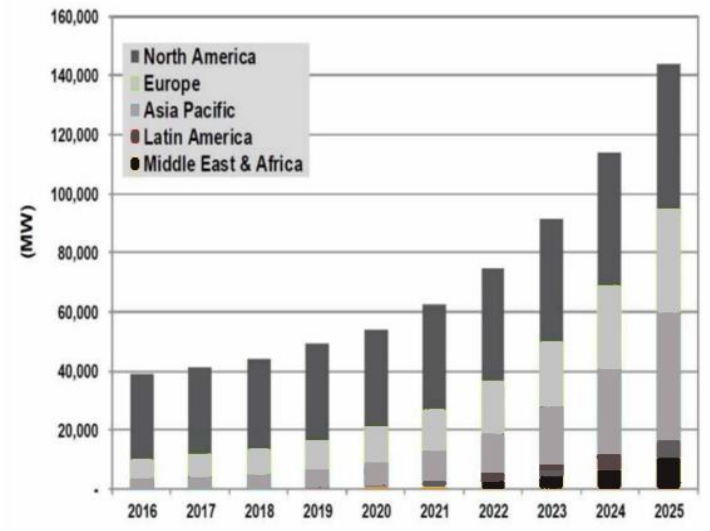

Figure 2. The volume of DSM in the world markets in 2016-2025.

Due to integration of DSM with information and communication technologies, a new term 'Smart Grid' has appeared. Smart grid is a modernized power supply network that uses information and communication networks and technologies to collect information about energy production and consumption, automatically improving the efficiency, reliability, economic benefits, and sustainability of electricity generation and distribution. Key players are expanding their presence globally through mergers and acquisitions, and upcoming smart grid projects in countries such as Australia, India, China, and Japan can attract more global players (managed consumption worldwide has reached $39 \mathrm{GW}$ in 2016 with the prospect of growth to $144 \mathrm{GW}$ in 2025) (Fig. 2).

In power systems all over the world, the introduction of demand management mechanism made it possible to organize centralized management of consumer resources in the amount of 2-6\% of peak demand, or $0.5-14 \mathrm{GW}$ of capacity (USA (PJM) - 13.9 GW, South Korea (KEPCO) - 3, 2 GW, Ontario, Canada (IESO) - $0.7 \mathrm{GW}$, UK (National Grid) - $0.5 \mathrm{GW}$ ), which allows consumers to reduce their electricity bills by $0.6-1.7 \%$ (Fig. 3). In addition, it should be noted that various opportunities for participation are implemented in different demand management mechanisms, for example:

- direct demand management (used primarily to ensure participation in demand management by residential consumers);

- guaranteed load shedding (used for emergency demand management, which is turned on last when absolutely necessary and therefore paid at a reduced rate).

- fast standby program (used to ensure the stability of the system frequency in case of an unexpected increase in demand or a decrease in supply and insufficient frequency regulation). 

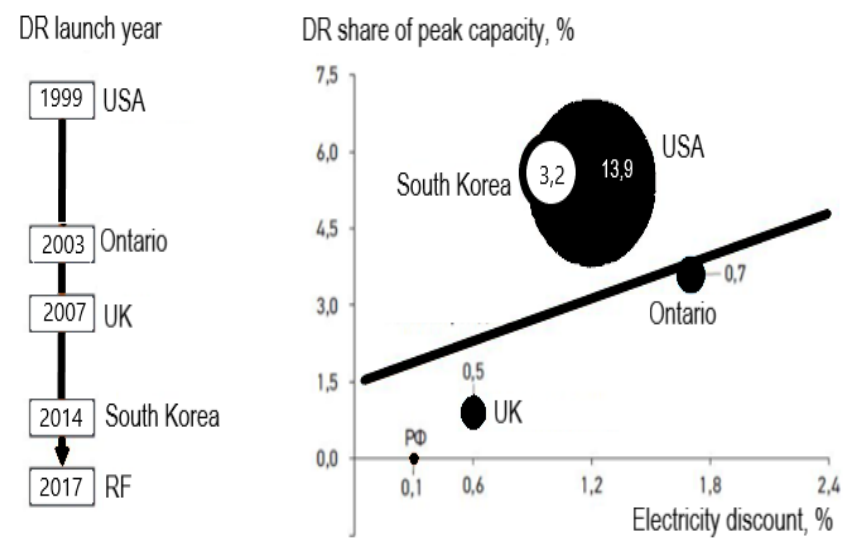

Figure 3. Dependence of actual participation in DR on remuneration (circle diameter - DR capacity, GW).

In Russia, Smart Grid technologies are implemented at the concept stage. The study of federal and regional regulatory documents issued in pursuance of the Law "On Energy Saving and Increasing Energy Efficiency" shows their lack of proper attention to the instrument for managing the demand for electricity.A survey of Russian publications on electricity demand management has revealed a fairly small number of studies on this issue. [7,8,9]. Many Russian scientists worked on the problem of demand management for electricity, their publications are devoted to the development of the concept and mechanisms of demand management, as well as to the study of the possibilities to adapt foreign experience of demand management in Russian practice.

\section{Managing power demand among retail consumers}

There are large (wholesale) and small motor (retail) consumers in the electricity market. As a rule, the energy consumption of every large consumer makes up several billion kilowatt-hours per year. With such significant volumes, it is economically more appropriate to maintain own structure responsible for energy supply through the wholesale electricity market than to turn to the services of energy sales organizations. Small-motor consumers are consumers, whose maximum power of power receiving devices within the balance sheet is less than $670 \mathrm{~kW}$. Small-scale consumers are mainly small and medium-sized businesses. These consumers do not have the opportunity to independently purchase electricity from the wholesale electricity market, and in order to manage their demand for electricity there exist the socalled load aggregators that will take over the organization and regulation of electricity consumption at certain hours. Managing the demand for retail electricity consumers in the future is an important tool for maintaining and regulating the balance of supply and demand in the electricity market. Demand management is a source of flexibility for the power system, which can be used to promptly regulate the balance of power in it, to improve system reliability, and to reduce prices. At the same time, demand management allows mass consumers to earn money in this market, making their useful contribution to improving the operation of the power system. Priority retail consumers that can make a significant contribution to demand management and whose demand aggregators should consider in the first place are those consumers whose load can be reduced (or "shifted" in time) without damage to core business.

These include facilities with ventilation and air conditioning systems, refrigerating and pumping equipment, electric heating, electric water heaters, i.e. industrial enterprises and commercial real estate, for example, shopping and entertainment centers, office centers, logistics infrastructure facilities (warehouses, container terminals, sorting centers), sports facilities. Experience shows that the development of demand management practice goes from "simple to complex": first, "lying on the surface" large consumers are covered, whose aggregation is relatively simple, but gradually smaller consumers are involved in the demand management, down to individual households. In order to organize the correct demand management, load aggregators will be used. Load aggregators are organizations that perform functions of managing the change in the load of a group of consumers in order to sell the set of regulatory capabilities of these consumers as a single object as a product or service in the retail electricity market or in the system services market. Load aggregators can be independent companies or electricity suppliers (sales companies).

Load aggregator:

- is looking for consumers who are potentially able to change consumption without damage to the technological cycle;

- assesses the unloading possibilities available to consumers;

- develops optimal algorithms for participation in demand management programs;

- equips consumers with the necessary automation equipment, instruments and devices.

- capex for converting the load from passive to controlled;

- capex and operating costs for integrating consumers into the information and measuring circuit;

- capex and operating costs for setting up commercial metering of electricity, ensuring settlements and payments;

Load aggregators, in turn, upon a preliminary command, offer the consumer to voluntarily limit the load to the pre-agreed level and for doing this provide incentives through payments for each $\mathrm{kWh}$ saved by consumers. In case of non-fulfillment of the reduction, the amount of the bonus is reduced, but the client does not bear any losses. If within two months the client has not completed a single reduction, he may be subject to penalties. As the main approaches to consumers, demand aggregators are supposed to use their so-called explicit (explicit, dispatchable) and implicit (implicit, nondispatchable) involvement in demand management. In explicit DR programs, the load is changed under the action of commands, or with the help of an automatic load control system from the dispatch center. Such governance implies financial incentives for the 
participating consumers and is most suitable for the industrial, commercial and agricultural sectors. Implicit DR is price-based or time-based and involves consumers using different types of time-differentiated tariffs that reflect the cost of electricity at different times. Implicit DR is primarily aimed at the small commercial and residential consumer sectors.

It is conditionally possible to distinguish six types of "configuration" of the DR (Fig. 2) [6]:

I) peak cut-off - reduction of the peak load without redistribution of demand for

II) electricity saving - proportional decrease in the demand schedule in all periods;

III) stimulation of electricity consumption - a proportional increase in the demand schedule in all periods;

IV)load shift - hourly control of the peak of the load graph;

V) filling of the share - covering the minimum load to align with the peak periods;

VI)flexible form of management - flexible continuous change in the configuration of the demand schedule.
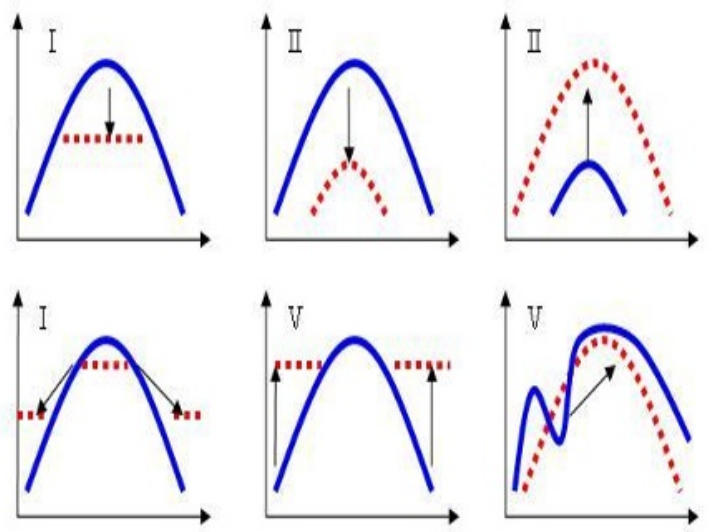

Figure 4. Types of "configuration" of demand response

Significant changes in the conventional concept of DR began to occur relatively recently in connection with the outlined increase in attractiveness over centralized power supply systems of distributed generation (DG).

This is largely due to the following [7]:

- location of generation directly in the consumption zone;

- relatively small capital investments and terms of commissioning of generating equipment;

- the possibility of using waste or by-products of production as a fuel, as well as local fuels.

Today, the leaders in the use of distributed generation are:

a)Enterprises of the oil and gas, mining, metallurgical, pulp and paper and chemical industries, the main feature of which is the availability of their own energy resources and remoteness from the main energy sources.
b)Agro-complexes, plants for processing plant products, logging and woodworking enterprises with a large amount of technological waste to be disposed of.

c) Cold storage facilities, warehouses - enterprises for which the presence of their own generation is necessary as a backup, and often more profitable in relation to centralized power supply

d)Production facilities with clear plans for the release of products and development prospects with relatively large volumes of power consumption, allowing for efficient loading and operation of their own generation, making it more profitable than power consumption from external sources.

It should be noted that in Russia, in contrast to European countries, where small-engine consumers in large part have their own renewable generation, centralized generation prevails. Hence the task is to find a mutual compromise for all participants in the DR process: generation of power supply organizations, load aggregators and consumers. Despite certain positive aspects, it is currently difficult to say that demand management in the conditions of the classical (centralized) electric power industry in Russia has positive factors in its application. From the power system point of view, demand management is certainly positive, but how interesting is this phenomenon to the consumer? Moreover, in Russian conditions, distributed generation is purely conditional. After all, it is no secret that renewable energy sources in Russia are inaccessible to the mass consumer and their use is under a big question in the near future. At the same time, the power industry in Russia has historically had a high degree of centralization, which again imposes a certain framework on the use of energy management. It follows that the main goal of our work is to find a certain compromise in the mutual benefit of load management for the centralized power industry, consumers and their possible intermediaries - load aggregators. Therefore, the goal of further work is to develop an evaluation model, which in turn will allow finding criteria for the efficiency of load management for small-engine consumers within the framework of solving the problem of mutual efficiency for the centralized power system, electricity consumers and their possible intermediaries - operators.

\section{Conclusion}

Summarizing all of the above, a number of conclusions can be drawn.

1. From the point of view of the power system, the DR brings a number of benefits associated with changing the nature of the load curve, filling its gaps, cutting off the load peaks. All these factors have a positive effect on the general regime of electricity consumption of the electric power system.

2.In considering the Russian electric power industry as a whole, it should be stated that the demand management plays a great role, since small investments of energy companies can be directed not to new construction, but to the industrial re-equipment of the existing facilities and increasing industrial reliability, it 
will become possible to reduce state budget expenditures to compensate for the invested risks and direct investments, and, besides, to maintain socially acceptable rates in the retail market.

3. However, the introduction of demand management requires a lot of preliminary study, since the historically developed concept of the centralized electric power industry in Russia does not allow the template application of the DR according to the scenarios of other countries.

\section{References}

1. Dzyuba A.P., Solovyova I.A. / Research of tools for managing demand for electricity consumption in the wholesale and retail electricity markets in Russia // Economics, Entrepreneurship and Law. 2016. Volume 6 No. 2.

2. IEA (International Energy Agency), «Re-Powering Markets. Market design and regulation during the transition to low-carbon power systems», Second Edition,(March2016);www.iea.org/publications/freep ublications/publication/REPOWERINGMARKETS. PDF.

3. Steven Nadel. Demand response programs can reduce utilities' peak demand an average of $10 \%$, complementing savings from energy efficiency programs. American Council for an Energy-Efficient Economy (ACEEE) (February 9, 2017); http://aceee.org/blog/2017/02/demand-responseprograms-can-reduce

4. Smart grid //. Electronic encyclopedia "Wikipedia".

- https://en.wikipedia.org/wiki/Smart_grid.

5. US National Energy Conservation Policy Act.

- http://www.encyclopedia.com/doc/1G23407400214.html.

6. Energy demand management // Electronic encyclopedia "Wikipedia".

- https://en.wikipedia.org/wiki/Energy_demand_mana gement.

7. Gitelman L. D. Energy demand management. Unique innovation for the Russian electric power industry: monograph / L.D. Gitelman, B.E. Ratnikov, M.V. Kozhevnikov, Yu.P. Shevelev. - Yekaterinburg, 2013 -- 120 p.

8. Gitelman L. D. Electricity Demand Management: Adapting Foreign Experience in Russia / L.D. Gitelman, B.E. Ratnikov, M.V. Kozhevnikov // Effective anti-crisis management. - 2013

- http://info.e-c-m.ru/magazine/76/eau_76_207.htm.

9. Gitelman L.D. Economics and business in the electric power industry: an interdisciplinary textbook / L.D. Gitelman, B.E. Ratnikov. - M .: Economics, 2013 .-$432 \mathrm{p}$. 